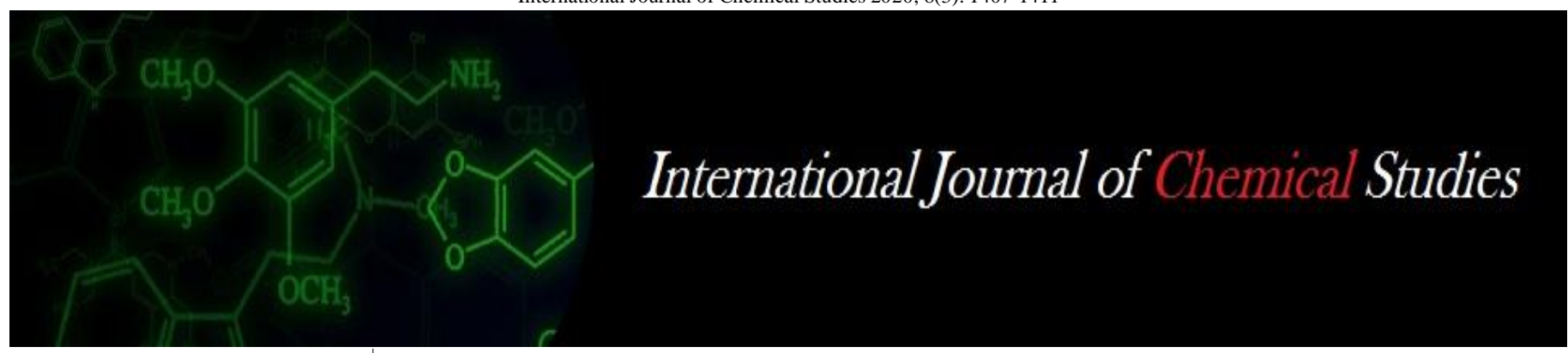

P-ISSN: 2349-8528

E-ISSN: 2321-4902

www.chemijournal.com

IJCS 2020; 8(3): 1407-1411

(C) 2020 IJCS

Received: 18-03-2020

Accepted: 20-04-2020

\section{Momita Konwar}

Department of Textiles and Apparel Designing, Faculty of Community Science, Assam Agricultural University, Jorhat, Assam, India

\section{Satvinder Kaur}

Department of Textiles and Apparel Designing, Faculty of Community Science, Assam Agricultural University, Jorhat, Assam, India

Rickey Rani Boruah Department of Textiles and Apparel Designing, Faculty of Community Science, Assam Agricultural University, Jorhat, Assam, India
Corresponding Author: Momita Konwar Department of Textiles and Apparel Designing, Faculty of Community Science, Assam Agricultural University, Jorhat, Assam, India

\section{Development of Eri union fabrics for diversified products}

\author{
Momita Konwar, Satvinder Kaur and Rickey Rani Boruah
}

DOI: https://doi.org/10.22271/chemi.2020.v8.i3s.9394

\begin{abstract}
The union fabrics were made from eri with cotton and eri with polyester. The $2 / 60$ s eri silk yarn was used as warp and 2/40s cotton and polyester yarns were used as weft to construct the eri union fabrics using three different weaves namely plain, twill and satin. The prepared eri $\mathrm{x}$ cotton and eri $\mathrm{x}$ polyester union fabrics and also the pure eri x eri fabrics were tested for different physical properties. Properties of union fabric developed in a traditional handloom using 60 s reed count. The quality parameters, viz., fabric tensile strength and elongation, crease recovery, drapability, thickness, abrasion, stiffness of the developed fabric, met essential apparel requirements. A comparative subjective evaluation of the fabric quality, viz., aesthetic appearance, luster, texture, was made with the help of a group of people from different age, educational and occupational background to examine the tactile properties as well as suitability of the fabric for the prepared products, all the respondents felt that eri $\mathrm{x}$ cotton twill, eri $\mathrm{x}$ polyester twill and eri $x$ polyester satin were good in appearance. Texture and luster were found to be medium to high. About a very few respondents felt that fabrics were crispy.
\end{abstract}

Keywords: Union fabric, eri, cotton, polyester

\section{Introduction}

In recent years, the fabrics of different blends and union fabrics are available in the market for various end uses. The raw material - yarn of different types are used for producing different varieties of fabrics to meet the fashion. Raw materials used for fabric construction are cotton, silk, wool, jute, synthetic, etc. (Azad and Jafrin, 2009) ${ }^{[5]}$. Union fabric is made by using different yarn in warp and weft direction. Union fabric is durable, crease resistant, absorbent, lustrous and resilient. Various kinds of union fabrics can be produced by combination of silk with cotton, rayon, ramie, polyester, acrylic, etc.to reduce the cost of the silk fabric as well as the weight of the fabric (Nayak et al., 2009) ${ }^{[13]}$.

Eri silk ranks next to tassar silk in commercial importance. Eri is a multivoltine silk spun from open- ended cocoons. In the year 2012-2013, the total eri raw silk production in India was $3116 \mathrm{MT}$ and the total useful silk waste available in the country was about 1.8 million $\mathrm{kg}$, of which, one- third was consumed by spun silk waste (ESW) (Dutta et al. 2000) ${ }^{[12]}$. Silk waste in rural areas is spoiled, as its use is not known. If all the available silk waste is properly kept and utilized for the spinning of $100 \%$ spun yarns or used in making blended yarns with fibers such as polyester, a good amount of foreign exchange can be earned by exporting finished goods instead of exporting silk waste at low prices.

In the reported work, an attempt has been made to developed union fabric besides blending. If eri is woven as a union fabric with other yarns, we can expect an attractive fabric with improved functional properties. In this type of fabrics the properties of two different yarns are combined together to get a new fabric having the properties of both the yarns. The Eri union fabric obtained will offer flexibility in choosing varieties of Eri fabric which would be costeffective yet attractive. Union fabric enables the weavers to combine two different sets of yarns so that good qualities are emphasized and poor qualities are minimized, thereby having the fabrics with better functional properties. Union fabrics of two different yarns offer most valuable possibilities because the two components are very dissimilar. Union fabrics if woven with eri warp and cotton weft and eri warp and polyester weft will create a variegated effect and the fabrics are expected to open up a new horizon for diversification of products other than 
wrappers and scarf. The produced materials would be cheaper and an artisan can expect to gain and learn more for a subsistence living.

\section{Materials and methods}

The union fabric used in this experiment was made from Eri with cotton and Eri with polyester. The eri yarn was collected from the Fabric plus, Silk industry Guwahati, Assam, India. The wooly white spun eri silk of $2 / 60$ s count was chosen for the study. Cotton and polyester yarns were selected 2/40s count and collected from local market Jorhat, Assam, India.

\section{Fabric preparation}

A plain, twill and satin weave fabrics were developed using a traditional handloom of $60 \mathrm{~s}$ reed count. $2 / 60 \mathrm{~s}$ yarn count were used for all the three (3) weaves i.e. plain, twill and satin weave. Eri silk yarn was used as warp in this study and eri, cotton and polyester yarns were used as weft to construct the eri union fabric.

\section{Determination of fabric properties}

Structural parameters of the fabric, such as fabric count (IS 1963-1969), thickness (IS-7702-1975), were measured by following standard methods. Cover factor was calculated separately for warp and weft using the expression recommended by Booth (1968) ${ }^{[1]}$. Bending length was measured by using a stiffness tester (Booth, 1968) [1] following BS 3356-1961.The test samples were tested for crease recovery as directed in the IS 4681:1968 method by using the Shirley's crease tester. Readings for both warp and weft were recorded separately.

The tensile strength and elongation was measured using Instron tensile tester following the ASTM test method: 22561, 1968. Drapability of a fabric with a circular specimen was directed by using a drape meter following the method recommended by Booth (1969). The abrasion resistance of a fabric consists of friction between the cloth and some other material was analyzed using 'Martindale Abrasion Resistance Tester'. The specimens were abraded as directed in IS test method: 12673-1989.Pilling property of a fabrics were rated by as directed by Booth (1968) ${ }^{[1]}$ ASTM D4970/D4970M box was rotated at $60 \mathrm{revaluation} / \mathrm{min}$ for $5 \mathrm{hr}$.

\section{Subjective evaluation of union fabrics}

For visual assessment of union fabrics and also the prepared products, a panel of 40 respondents of different age, education and occupational groups. Some important tactile properties, such as general appearance, texture, luster, handle and suitability of a fabric for making diversified products were assessed by the respondents with the help of a questionnaire.

\section{Results and discussion Mechanical properties of eri and union fabrics}

The mechanical properties of pure eri and union fabrics were evaluated and presented in Table 1. Fabric count in woven textile material is the number of warp yarn (ends) and weft yarns (picks) per inch of a fabric. Determination of count was done with the help of a pick glass as directed by Booth (1969). It is revealed from the table that the slight variation was seen in the weft direction of fabric count sample. This may be due to the cotton and polyester yarn of $2 / 40$ s count was used as weft for all sets of weaves, or may be because of yarn type and compactness of weave. The cover factor results shows that the warp cover factor of all the test samples of three different weaves were slightly higher side, may be due to the coarser yarn count of eri and also the 2 ply yarn structure which was used as warp for all the sets of fabrics. Thickness $(\mathrm{mm})$ is the distance between the upper and lower surface of the material measured under a specific pressure using "Shirley's thickness" tester as directed by Booth (1969). The eri x polyester satin weave union fabric was found to be thinner followed by eri $\mathrm{x}$ polyester twill union fabric. A marginal difference in the fabric stiffness was observed in both the warp and weft direction of eri $\mathrm{x}$ polyester satin weave union fabric, compared with other pure eri fabric may be due to the due to yarn type, compactness of weave, lowest thickness. The crease recovery of eri $\mathrm{x}$ polyester satin weave fabric resulted in better recovery followed by eri $\mathrm{x}$ polyester twill weave fabric, than the pure eri $x$ eri fabrics. This may be attributed to the high resiliency of polyester fiber and the type of weave.

Table 1: Mechanical properties of fabrics

\begin{tabular}{|c|c|c|c|c|c|c|c|c|c|c|}
\hline \multirow{2}{*}{ Weave type } & \multirow{2}{*}{ Fabrics } & \multicolumn{2}{|c|}{ Fabric count (thread/inch) } & \multicolumn{2}{|c|}{ cover factor $(\mathrm{Ne})$} & \multirow{2}{*}{ Fabric thickness (mm) } & \multicolumn{2}{|c|}{ Fabric stiffness (cm) } & \multicolumn{2}{|c|}{ Crease recovery (degree) } \\
\hline & & Warp & Weft & Warp & Weft & & Warp & Weft & Warp & Weft \\
\hline \multirow{3}{*}{ Plain } & EEP & 45 & 46 & 10.79 & 9.48 & 0.52 & 3.28 & 2.60 & 82.25 & 87.00 \\
\hline & ECP & 44 & 45 & 9.44 & 7.87 & 0.41 & 2.63 & 2.85 & 93.25 & 102.50 \\
\hline & EPP & 47 & 51 & 8.92 & 6.54 & 0.45 & 2.70 & 2.80 & 94.25 & 121.00 \\
\hline \multirow[t]{3}{*}{ Twill } & EET & 42 & 44 & 11.26 & 10.54 & 0.53 & 3.20 & 3.20 & 106.00 & 99.75 \\
\hline & ECT & 46 & 52 & 11.7 & 9.26 & 0.45 & 2.73 & 3.13 & 112.25 & 114.75 \\
\hline & EPT & 44 & 57 & 11.3 & 9.12 & 0.38 & 2.60 & 2.78 & 126.75 & 122.00 \\
\hline \multirow{3}{*}{ Satin } & EES & 46 & 45 & 10.58 & 9.86 & 0.52 & 3.13 & 2.78 & 89.75 & 94.25 \\
\hline & ECS & 43 & 52 & 10.34 & 9.19 & 0.47 & 2.70 & 2.38 & 110.75 & 123.25 \\
\hline & EPS & 44 & 58 & 10.18 & 9.3 & 0.34 & 1.70 & 1.55 & 127.75 & 125.25 \\
\hline
\end{tabular}

\section{Functional properties of Eri and union fabrics}

Table 2. Shows that the tensile strength of eri $\mathrm{x}$ polyester union fabrics resulted in better tensile strength in both warp and weft direction of all three weaves. The tensile strength in the weft direction was much more than in the warp direction this may be attributed to the polyester yarn which is stronger compared to eri and cotton yarns. A marginal increase was observed in the elongation (\%) of warp direction of all the weaves compared with weft. This might be due to eri silk yarn which is used in warp direction of all the weaves, or may be due to the inherent higher elongation properties of eri silk yarn as described by Hazarika et al.2017. The abrasion resistance of eri union fabrics were exhibited better resistance to abrasion than in pure eri fabric. It may be because of polyester yarn which was finer in structure and have less thickness, resulting into better abrasion resistance.

Drape is the ability of a fabric to hang in a graceful fold. Fabric drape is the extent to which a fabric will deform when it is allowed to hang under its own weight (Shinkle 1940) ${ }^{[11]}$. Drapability of a fabric is a combined effect of several factors 
such as shear rigidity, weight, thickness and some other parameters. The eri union fabrics show a balanced drapability than the pure eri fabrics may be due to stiffness of eri yarn. Since drape coefficient of eri union fabrics of all the three weaves was higher than pure eri fabrics of three respective weaves, this union fabrics can be effectively used for various garment styles with graceful folds. The pilling ratings of all union fabrics of three weaves shows better ratings then the pure eri fabric.

Table 2: Functional properties of fabrics

\begin{tabular}{|c|c|c|c|c|c|c|c|c|c|}
\hline \multirow{2}{*}{$\begin{array}{c}\text { Weave } \\
\text { type }\end{array}$} & \multirow[t]{2}{*}{ Fabrics } & \multicolumn{2}{|c|}{$\begin{array}{c}\text { Fabric Tensile strength } \\
(\mathrm{kg})\end{array}$} & \multicolumn{2}{|c|}{$\begin{array}{c}\text { Fabric elongation } \\
(\%)\end{array}$} & \multicolumn{2}{|c|}{ Abrasion resistance } & \multirow[t]{2}{*}{$\begin{array}{c}\text { Drape } \\
\text { coefficient }(\%)\end{array}$} & \multirow[t]{2}{*}{ Pilling (rating) } \\
\hline & & Warp & Weft & Warp & Weft & No. of cycles & Loss of mass $(\%)$ & & \\
\hline \multirow{3}{*}{ Plain } & EEP & 41.01 & 42.31 & 20.01 & 19.13 & 700 & 4.91 & 43.92 & 3(hairy\& severe pilling) \\
\hline & $\mathrm{ECP}$ & 42.57 & 41.60 & 25.09 & 21.44 & 715 & 3.57 & 46.30 & 2(hairy) \\
\hline & EPP & 49.10 & 65.19 & 28.67 & 26.09 & 920 & 3.37 & 58.04 & 1(hairy \&slight pilling) \\
\hline \multirow{3}{*}{ Twill } & EET & 42.85 & 55.22 & 19.72 & 16.82 & 825 & 4.21 & 44.70 & 3(hairy\& severe pilling) \\
\hline & ECT & 42.36 & 77.12 & 18.85 & 13.18 & 710 & 4.68 & 57.04 & 2(hairy) \\
\hline & EPT & 52.26 & 59.03 & 21.57 & 18.11 & 942 & 3.04 & 58.29 & 1(hairy \&slight pilling) \\
\hline \multirow{3}{*}{ Satin } & EES & 44.32 & 65.33 & 18.95 & 17.21 & 745 & 3.89 & 41.62 & 3(hairy\& severe pilling) \\
\hline & ECS & 41.80 & 34.22 & 26.62 & 16.75 & 730 & 5.16 & 45.07 & 2(hairy) \\
\hline & EPS & 44.80 & 70.82 & 26.95 & 18.31 & 827 & 3.24 & 47.67 & 1(hairy \&slight pilling) \\
\hline
\end{tabular}

\section{Subjective evaluation of eri union fabric}

In general, the respondents opined that the union fabrics of cotton \& polyester combinations were having a better aesthetic appearance than the other fabrics of three different weaves. It may be attributed to the cotton \& polyester yarn or different weave type. All the respondents felt that eri with cotton and eri with polyester was good in appearance in respect of pure eri fabrics of all three weaves. It was revealed from the table 3 that the tactile properties of all union fabrics were improved, it may be cause of two different yarns are combine together by having the qualities of both the yarn. This is apparent in Figure 1.

Table 3: Respondents opinion on the visual appearance of fabrics (\%)

\begin{tabular}{|c|c|c|c|c|c|c|c|c|c|}
\hline Parameter & Grade & EEP & ECP & EET & ECT & EPT & EES & ECS & EPS \\
\hline \multirow{3}{*}{ General appearance } & Good & 87.5 & 90 & 92.5 & 100 & 100 & 95 & 95 & 100 \\
\hline & Fair & 12.5 & 10 & 7.5 & 0 & 0 & 5 & 5 & 0 \\
\hline & Poor & 0 & 0 & 0 & 0 & 0 & 0 & 0 & 0 \\
\hline \multirow{3}{*}{ Texture } & Fine & 0 & 0 & 0 & 7.5 & 0 & 0 & 12.5 & 0 \\
\hline & Medium & 100 & 100 & 100 & 92.5 & 100 & 100 & 87.5 & 100 \\
\hline & Rough & 0 & 0 & 0 & 0 & 0 & 0 & 0 & 0 \\
\hline \multirow{3}{*}{ Luster } & High & 0 & 0 & 0 & 50 & 100 & 0 & 50 & 100 \\
\hline & Moderate & 100 & 100 & 100 & 50 & 0 & 100 & 50 & 0 \\
\hline & Low & 0 & 0 & 0 & 0 & 0 & 0 & 0 & 0 \\
\hline \multirow{3}{*}{ Handle (feel) } & Soft & 92.5 & 92.5 & 95 & 100 & 100 & 97.5 & 95 & 100 \\
\hline & Crispiness & 7.5 & 7.5 & 5 & 0 & 0 & 2.5 & 5 & 0 \\
\hline & Stiffness & 0 & 0 & 0 & 0 & 0 & 0 & 0 & 0 \\
\hline
\end{tabular}

The respondent opinion on suitable end uses of developed fabric is shown in Table 4. As per respondents' feedback, the developed fabric may be used for some selective products,
Waist coat, Tie, jackets, stole and some other furnishing items.

Table 4: Respondent's opinion on aesthetic and handle properties of prepared products (\%)

\begin{tabular}{|c|c|c|c|}
\hline \multicolumn{2}{|c|}{ Suitability \% } & Yes & No \\
\hline Fabric & Products & 100 & 0 \\
\hline EEP & Waist coat & 95 & 5 \\
\hline EET & Tie & 100 & 0 \\
\hline EES & Stole & 100 & 0 \\
\hline ECP & Cushion cover & 97.5 & 2.5 \\
\hline ECT & Top & 95.0 & 5 \\
\hline ECS & Jacket & 100 & 0 \\
\hline EPP & Cushion cover & & 0 \\
\hline
\end{tabular}




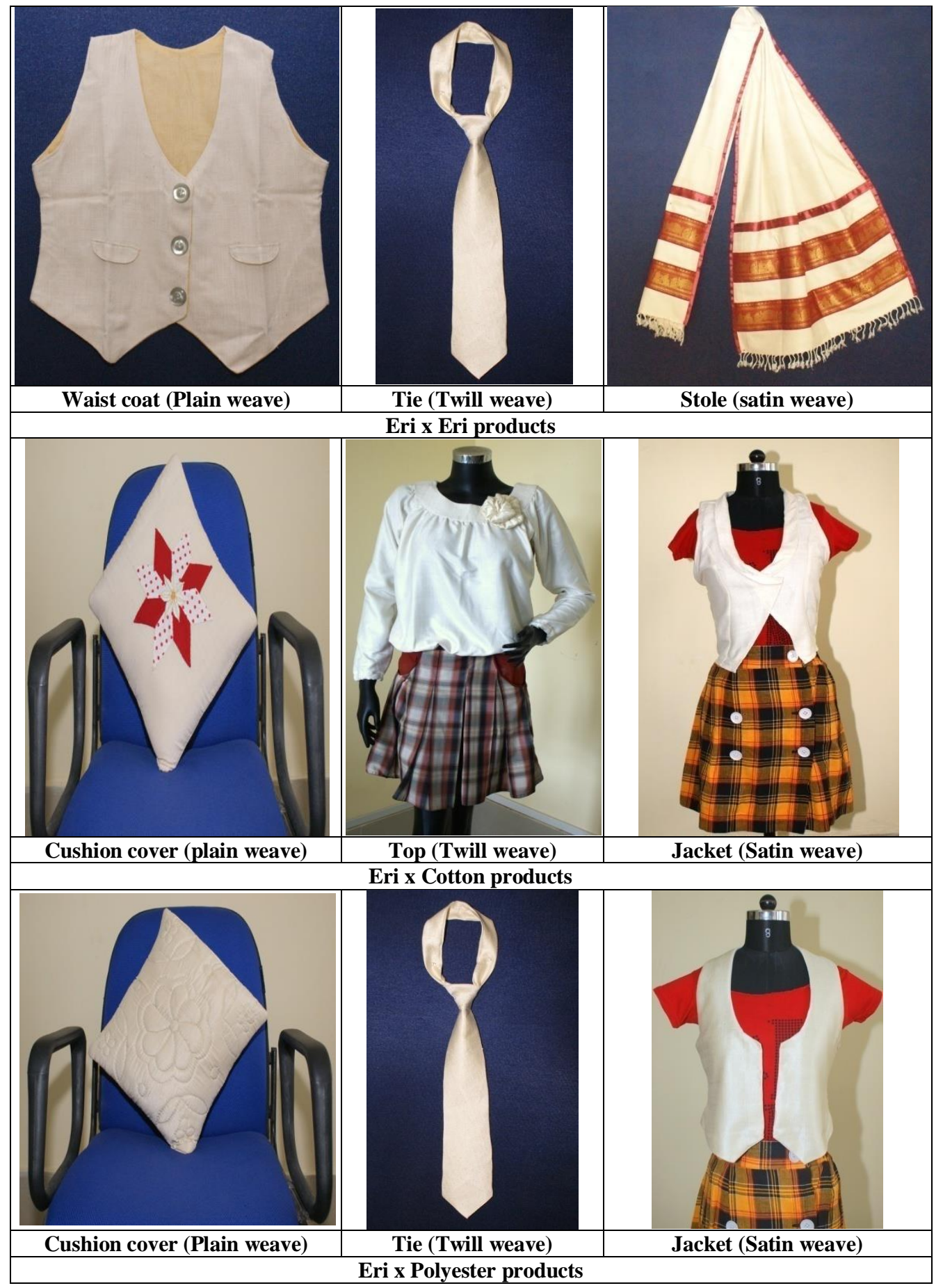

Fig 1: Diversified products of Eri and its union fabrics

\section{Conclusion}

Union fabric is a textile fabric which is used to weave in two different yarns in warp and weft. The main motive of this study was to combine two different yarns with eri so as emphasized good qualities and minimized poor qualities of a fabrics. The qualities of a fabric for making diversified products were analyzed. The fabrics were made on a conventional handloom and the suitability of a fabric for making different products was assessed by respondents from different age, educational, and occupational groups. From the investigation, it was observed that eri $\mathrm{x}$ cotton and eri $\mathrm{x}$ polyester union fabrics had better functional properties with increasing tensile strength, abrasion resistance and drapability of fabric keeping at par eri $\times$ eri fabrics. Hence it is concluded that after making erixcotton and erixpolyester union fabric, the fabric become more strength, durable, lighter in weight and have increased drapabality. Besides this, fabrics have unique appearance, and provide extra luster. Eri union fabrics are best suited for making diversified products such as dress waist coat, tie, cushion cover, stole etc. and also best suited for making baby blankets and jackets for winter seasons. Therefore, development of union fabrics will create a variety in fabric types and cater to the present fashion world.

\section{References}

1. Booth JE. Principles of textile testing. Third edition. London: Newness Butter Worth. 1968; 209, 215, 309, 315, 272, 275.

2. Oommen PJ. Eri - A silk for the new millennium. Indian Silk. 2003; 41(12):2.

3. Somashekar TH. Recent advances in eri silk spinning, weaving and future properties. Indian Silk. 2003; 41(12):49-52. 
4. Arora R, Sharma S. Physical properties silk based union fabric. J. Ind. Silk. 2010; 49(2):24-25.

5. Azad AK, Jafrin S. Study on the effect of size material on jute-cotton union fabric. Daffodil Int. Univ. J. Sci. Technol. 2009; 4(1):42-44.

6. Desai A. Properties of union fabric. Man-made Text. Ind. 2008; 51(6):379-384.

7. Itagi MR, Sreenivasa Vijaykumar HL, Nadiger GS. Development of Eri silk blended fabrics and study of their properties. Man-made Text. Ind. 2006; 49(2):47-50.

8. Gogoi N, Kalita BB. Eri silk- its properties and processing. $1^{\text {st }}$ edition, Printed- Arindam offset \& Imaging System, 2009, 5-8.

9. Hazarika P, Hazarika D, Kalita B, Gogoi N, Jose S, Basu G. Development of Apparels from silk waste and Pineapple Leaf Fiber. Journal of Natural fibers, 2017. doi.org/10.1080/15440478.2017.1333071

10. Upadhyay RN, Das PK. Eri spinning on Ambar Charakha - An experience. Indian Silk. 2003; 41(2):53-54.

11. Skinkle JH. Textile testing: Physical, chemical and microscopical. New Delhi, India: D.B. Taraporevala, 1940.

12. Dutta RN, Sarma ML, Debraj Y, Das PK, Benchamin $\mathrm{KV}$. Eri culture in northeast India.Seminar on sericulture R\& D in muga \& eri. Lahdoigarh, Jorhat, India: Central Muga \& Eri Res. \& Training Institute, 2000.

13. Nayak PK, Purj SK, Chatterjee KN. Comfort properties of suiting fabrics, Indian Journal of Fiber and Textile Research. 2009; 34:122-128. 